\title{
Acute effect of thymoquinone on action potential and ionic currents of rat cardiac myocytes
}

\author{
Mercan T, Yamasan BE, Erkan O, Ozdemir S \\ Akdeniz University, Faculty of Medicine Department of Biophysics, Antalya, Turkey. osemir@akdeniz.edu.tr
}

\begin{abstract}
OBJECTIVES: This study aims to investigate the acute effects of thymoquinone (TQ) which has been suggested to be a cardioprotective agent, on ventricular myocytes.

METHODS: Freshly isolated rat ventricular myocytes were exposed to TQ and using standard whole-cell patch-clamp technique action potential (AP), sodium current $\left(I_{\mathrm{Na}}\right)$, L-type calcium current $\left(\mathrm{I}_{\mathrm{CaL}}\right)$ and transient outward potassium current $\left(\mathrm{I}_{\mathrm{to}}\right)$ were measured.

RESULTS: TQ prolonged the duration of AP and decreased the peak value compared to that of control myocytes. Consistently, it inhibited $I_{\mathrm{Na}}$ in a concentration-dependent manner and shifted the channel kinetics to more hyperpolarized voltages. Besides, TQ not only inhibited $\mathrm{I}_{\text {to }}$ and $\mathrm{I}_{\mathrm{CaL}}$ but also significantly attenuated the isoproterenol-induced increase in $\mathrm{I}_{\mathrm{CaL}}$.

CONCLUSION: The effect of TQ on cardiomyocytes has been demonstrated for the first time. TQ changes AP morphology along with ionic currents and alleviates $\beta$-adrenergic response in adult ventricular myocytes. These results indicate that TQ may be considered as a therapeutic agent in cases such as diabetic cardiomyopathy and cardiac hypertrophy, wherein the $\beta$-adrenergic system is over-activated (Tab. 2, Fig. 6, Ref. 30). Text in PDF www.elis.sk

KEY WORDS: thymoquinone, action potential, ionic currents, $\beta$-adrenergic response, ventricular myocytes.
\end{abstract}

\section{Introduction}

Flavonoids in plants have been used in the treatment of cardiovascular diseases (CVD) due to their anti-inflammatory, antioxidant and vasodilator effects $(1,2)$. Nigella sativa (NS) known as black seed, is one of the most studied plants in the recent period due to its distinct characteristics and it has various bioactive components such as thymoquinone (TQ) (3). TQ is derived from a variety of plants belonging to the family of NS seeds (4). This plant grows primarily in the Middle East and some West Asian regions (5). TQ is suggested to have a protective effect against CVD, neurodegenerative diseases, diabetes, inflammation and oxidative stress (6-10) due not only to its anti-inflammatory effect by inhibiting cyclooxygenase and 5-lipoxygenase enzymes but also anti-oxidant effect by scavenging reactive oxygen species (ROS) (11-13).

The protective effect of TQ on the heart has been experimentally shown by applying various cardiotoxic chemical agents

Akdeniz University, Faculty of Medicine, Department of Biophysics, Antalya, Turkey

Address for correspondence: S. Ozdemir, Akdeniz University, Faculty of Medicine, Department of Biophysics, Antalya, Turkey. Phone: +90.2422496907

Acknowledgement: This work was supported by Akdeniz University Research Projects Coordination Unit grant (Project number: TSA-2019-4784). mostly to animal models (14). In diabetic rats, TQ treatment reduced the oxidative stress damage and endothelial nitric oxide synthase protein expression while the increase in cyclooxygenase-2 level, tumor necrosis factor- $\alpha$ (TNF- $\alpha$ ) and interleukin- $\beta 6$ levels were mitigated $(15,16)$. This is due to the fact that TQ significantly decreases the caspase- 3 activity and phosphorylated protein kinase B (Akt) protein expression levels, and thereby reduces the oxidative stress, inflammation and apoptosis via phosphatidylinositol 3-kinase (PI3K)/Akt pathway (16). Besides, TQ administration has reduced the level of thiobarbituric acid reagent substances and prevented ISO (isoproterenol)-induced cardiotoxicity by increasing the oxidized/reduced glutathione ratio and glutathione reductase as well as superoxide dismutase levels in myocardial tissues (17). In another study, Al-Shabanah et al. found that TQ administration inhibited doxorubicin (DOX) induced cardiotoxicity by lowering serum creatine kinase and lactate dehydrogenase levels (18).

Despite it has been shown to exert a significant cardioprotective effect in disease models induced by chemical agents such as DOX, streptozotocin and ISO, the mechanism of this impact on contractile cells of the heart is unknown yet. Therefore, we aimed to test whether TQ affects the electrical activity of heart ventricular myocytes by examining the action potential (AP) characteristics and underlying ionic currents. Besides, the effect of TQ on the $\beta$-adrenergic response of L-type $\mathrm{Ca}^{2+}$ channels was also studied, since it has not been shown before. 


\section{Materials and methods}

Animals

Three-month-old male Wistar rats were used in the present study. They were kept in a room with temperature $20 \pm 2{ }^{\circ} \mathrm{C}$ and a light-dark cycle of $12 \mathrm{~h}$. All experimental protocols were approved by the committee for the ethical use of experimental animals at the Akdeniz University (856-2019.02.002).

\section{Isolation of ventricular myocytes}

All animals were anesthetized with sodium pentobarbital (50 $\mathrm{mg} / \mathrm{kg}$, ip.) and the thoracic cavity of the rats was opened, and the hearts excised rapidly. After that, hearts were transferred to a cold standard Tyrode's solution containing $137 \mathrm{NaCl}, 5.4 \mathrm{KCl}$, 11.8 HEPES, $0.5 \mathrm{MgCl}_{2}, 1.5 \mathrm{CaCl}_{2}$ and 10 glucose (all in $\mathrm{mM}$ ) at a $\mathrm{pH}$ of 7.35. After aortic cannulation, the extracted heart was attached to the Langendorff apparatus and perfused retrogradely through the coronary arteries with $\mathrm{Ca}^{2+}$-free solution containing $137 \mathrm{NaCl}, 5.4 \mathrm{KCl}, 1.2 \mathrm{MgSO}_{4}, 1.2 \mathrm{KH}_{2} \mathrm{PO}_{4}, 6$ HEPES and 20 glucose (all in $\mathrm{mM}$ ) at a $\mathrm{pH}$ of 7.2 , (bubbled with $95 \% \mathrm{O}_{2}$ ) for

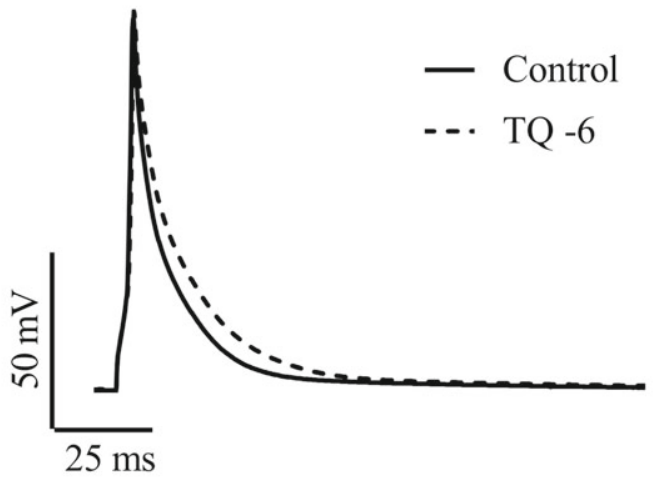

time (ms)

A

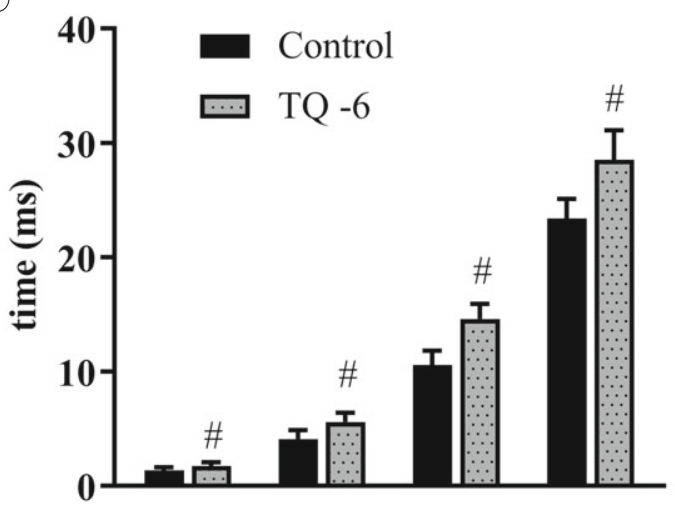

APD25 APD50 APD75 APD90
5 min. Following $\mathrm{Ca}^{2+}$ free solution, an enzymatic solution containing $0.8 \mathrm{mg} / \mathrm{mL}$ collagenase (Collagenase A Roche) and 0.07 $\mathrm{mg} / \mathrm{mL}$ protease (Sigma type XIV) was given to the heart for approximately $20 \mathrm{~min}$. At the end of digestion period, the heart was placed in a small beaker and minced into small pieces. The cells were then passed through a nylon mesh and washed several times using $\mathrm{Ca}^{2+}$-free standard Tyrode's solution. For the adaptation of the cells, the $\mathrm{Ca}^{2+}$ level in the medium was gradually increased at 5-minute intervals. The recording of data was started approximately $1 \mathrm{~h}$ after the isolation of ventricular myocytes and all data were collected at $36 \pm 1{ }^{\circ} \mathrm{C}$.

\section{Electrophysiological recordings}

Action potential

AP was recorded at a frequency of $1 \mathrm{~Hz}$ using the currentclamp mode of the patch-clamp amplifier (Axon 200B, Molecular Devices). The patch pipettes were prepared using capillary borosilicate glasses with 2-2.5 $\mathrm{M} \Omega$ resistance. Pipette solution (mM): $120 \mathrm{KCl} ; 6.8 \mathrm{MgCl}_{2}$; $5 \mathrm{Na}_{2}$ ATP; 5 ; $0.4 \mathrm{Na}_{2}$ GTP; 10 EGTA; 4.7 $\mathrm{CaCl}_{2} ; 20$ HEPES $(\mathrm{pH}=7.4)$. The AP traces were obtained by

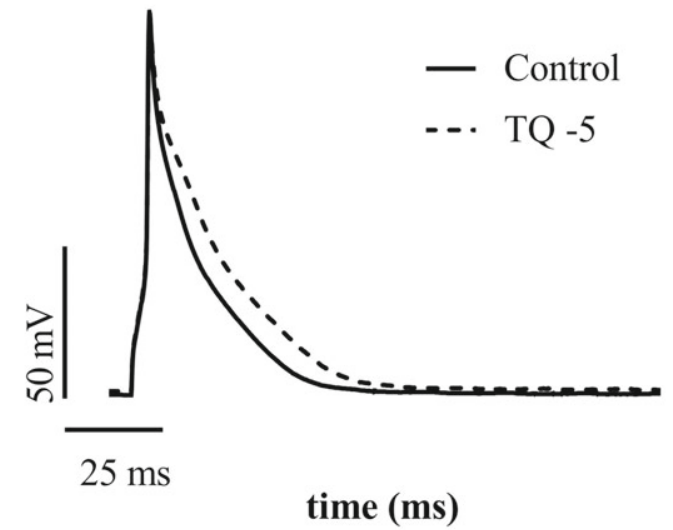

B

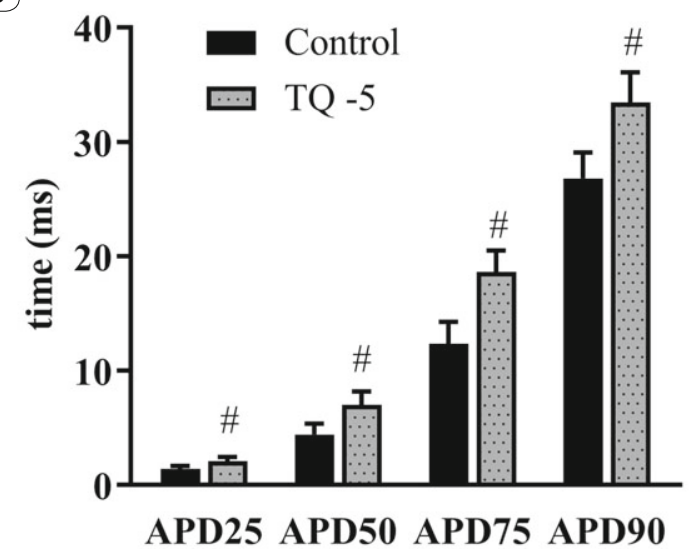

Fig. 1. Effect of TQ-6 $\left(10^{-6} \mathrm{M}\right)$ and TQ-5 $\left(10^{-5} \mathrm{M}\right)$ on action potential (AP) characteristics of ventricular myocytes. Both TQ-6 (A) and TQ-5 (B) change the average repolarization time of AP presented as APD25, APD50, APD75 and APD90. AP were elicited at a stimulation rate of $1 \mathrm{~Hz}$. Both concentrations of TQ decrease peak of AP. \# $p<0.05$ versus control ( $n=10$ cells for TQ-6 and $n=9$ for TQ-5). 
424-431

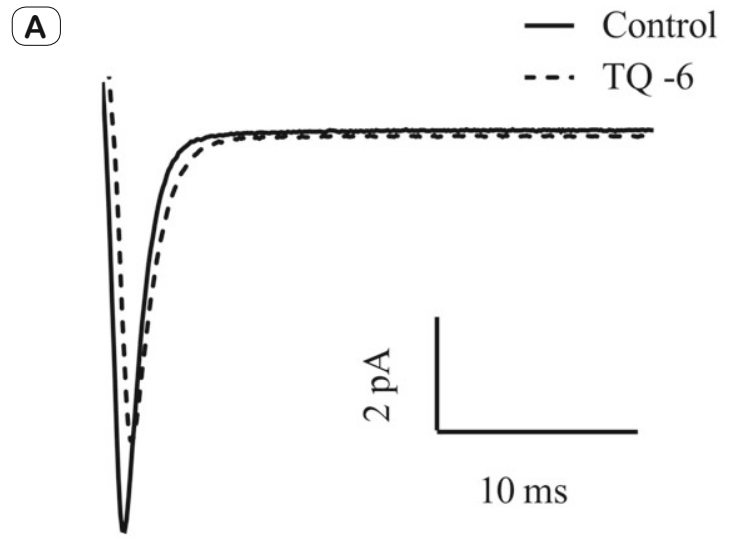

(C)

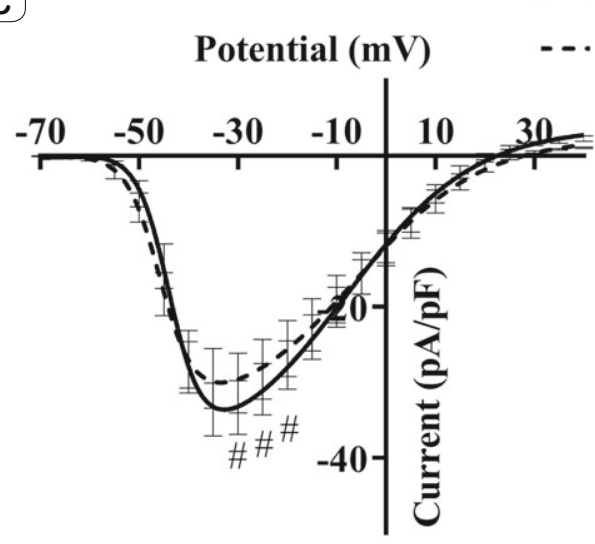

(B)
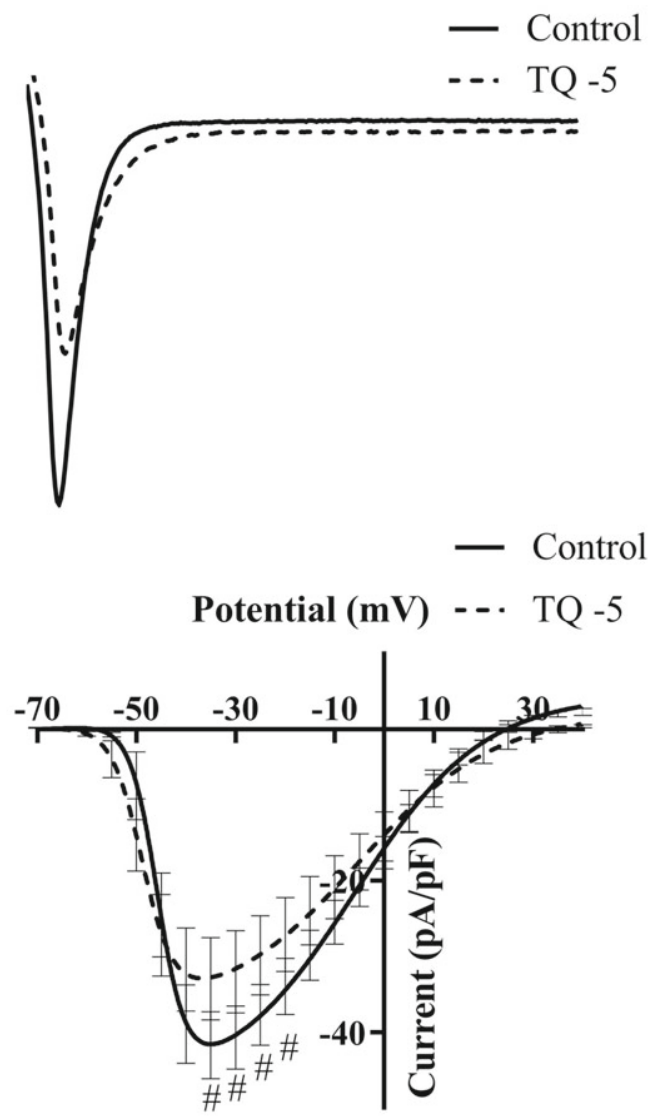

Fig. 2. Effect of $\mathrm{TQ}$ administration on $\mathrm{Na}^{+}$currents of ventricular myocytes. An example of superimposed $\mathrm{Na}^{+}$current recordings from $\mathrm{Control}$ and TQ-6 $\left(10^{-6} \mathrm{M}\right)(\mathrm{A})$, TQ-5 $\left(10^{-5} \mathrm{M}\right)(\mathrm{B})$. Peak current-voltage relationship for Control and TQ-6 (C). Peak current-voltage relationship for Control and TQ-5 (D). \# $p<0.05$ versus control ( $n=9$ cells for TQ-6 and $n=8$ for TQ-5).

stimulating the cell by depolarizing pulses above the threshold. Then 25, 50, 75, $90 \%$ (APD25, 50, 75, 90) of the repolarization phases of the AP were calculated using Clampfit software (Version 10, Molecular Devices, USA).

\section{Sodium current}

Sodium current $\left(\mathrm{I}_{\mathrm{Na}}\right)$ was measured using the whole-cell configuration of patch-clamping. The pipette solution contained $(\mathrm{mM})$ : 0.4 NaGTP; 5 MgATP; $120 \mathrm{CsCl}_{2}$; 5 EGTA; 20 HEPES ( $\mathrm{pH}=7.20$ ) and cell were superfused with a low $\mathrm{Na}^{+}$-HEPES solution containing (mmol/1: $\mathrm{NaCl} 40, \mathrm{~N}$-methyl-D-glucamine glucosamine 77, $\mathrm{CsCl} 20, \mathrm{CaCl}_{2} 1.8, \mathrm{MgCl}_{2} 1.8, \mathrm{CdCl}_{2}$ 0.2, glucose 10, HEPES 10 and $\mathrm{pH}$ at 7.4 with $\mathrm{HCl}$ ). To characterize the voltage dependence of peak $\mathrm{I}_{\mathrm{Na}}$, cells were held at $-80 \mathrm{mV}$, and then a pre-pulse protocol (from $-80 \mathrm{mV}$ to $-120 \mathrm{mV}$ ) followed by increasing voltage steps ( $200 \mathrm{~ms}$, from $-70 \mathrm{mV}$ to $+40 \mathrm{mV}$ in $5 \mathrm{mV}$ steps) was applied. After I-V measurement, $\mathrm{Na}^{+}$current kinetic recordings were taken. For activation, cells were held at $-120 \mathrm{mV}$, and $100 \mathrm{~ms}$ voltage steps were applied from $-70 \mathrm{mV}$ to $-20 \mathrm{mV}$ in $5 \mathrm{mV}$ increments. However for inactivation measurements, cells were held at -70 $\mathrm{mV}$ and $150 \mathrm{~ms}$ voltage steps were applied from $-130 \mathrm{mV}$ to -50 $\mathrm{mV}$ in $5 \mathrm{mV}$ increments. After each step, cells were held at -35
$\mathrm{mV}$ for $50 \mathrm{~ms}$. All data were normalized to the peak conductance $\left(\mathrm{G}_{\max }\right)$ and fit to a two-state Boltzmann distribution (19).

\section{Transient outward potassium current}

Transient outward potassium current $\left(\mathrm{I}_{\text {to }}\right)$ was measured using the whole-cell configuration of voltage-clamp amplifier. The electrodes were prepared using capillary borosilicate glasses. The pipette solution was contained (in $\mathrm{mM}$ ); $125 \mathrm{~L}$-Aspartate potassium; $20 \mathrm{KCl} ; 10 \mathrm{NaCl} ; 5 \mathrm{MgATP} ; 10$ K-HEPES (pH = 7.2). $\mathrm{CdCl}_{2}$ $(250 \mu \mathrm{M})$ was also added to the intra-capillary medium to block $\mathrm{Ca}^{2+}$ currents. Pre-pulse to $-45 \mathrm{mV}$ from a holding potential of $-80 \mathrm{mV}$ was used to inactivate $\mathrm{Na}^{+}$current. Then, $\mathrm{I}_{\text {to }}$ recordings were obtained by applying 2 seconds depolarizing pulses at +50 $\mathrm{mV}$. $\mathrm{I}_{\text {to }}$ density was calculated by subtracting the current values in the last part of the $2 \mathrm{~s}$ pulse from the peak values of the currents. Then, the measured currents were normalized to cell capacitance and presented as current density.

\section{L-type calcium current}

The electrodes were prepared using capillary borosilicate glass with 2-2.5 M $\Omega$ tip resistance. Pipette solution containing (in $\mathrm{mM}$ ) 120 Cs-Aspartate; $20 \mathrm{CsCl} ; 5 \mathrm{MgATP} ; 10 \mathrm{NaCl} ; 10$ HEPES; 0.4 
A

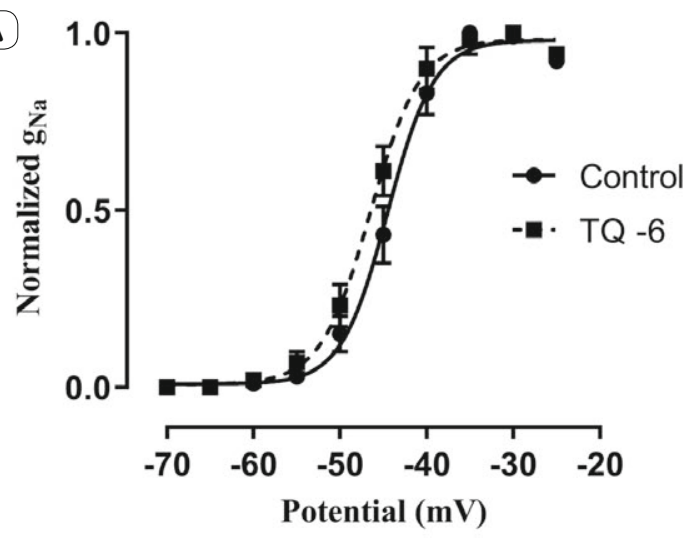

C

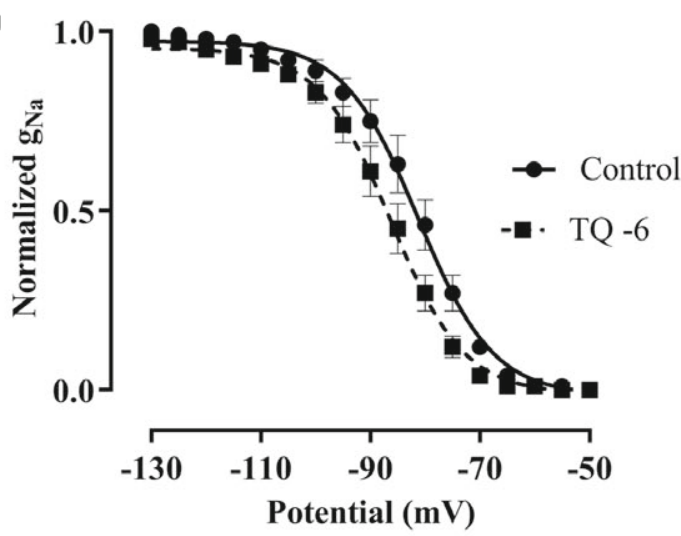

B

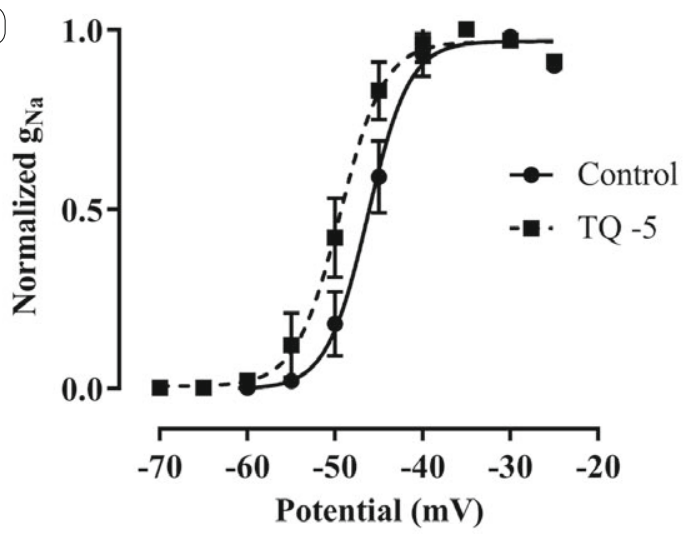

(D)

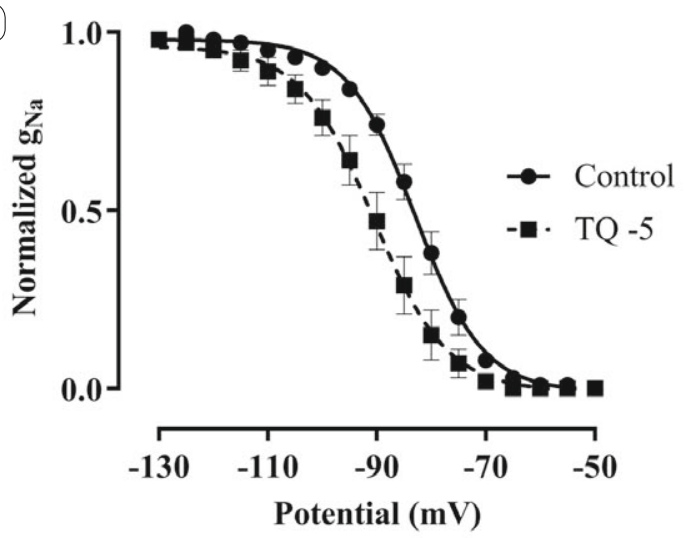

(E)

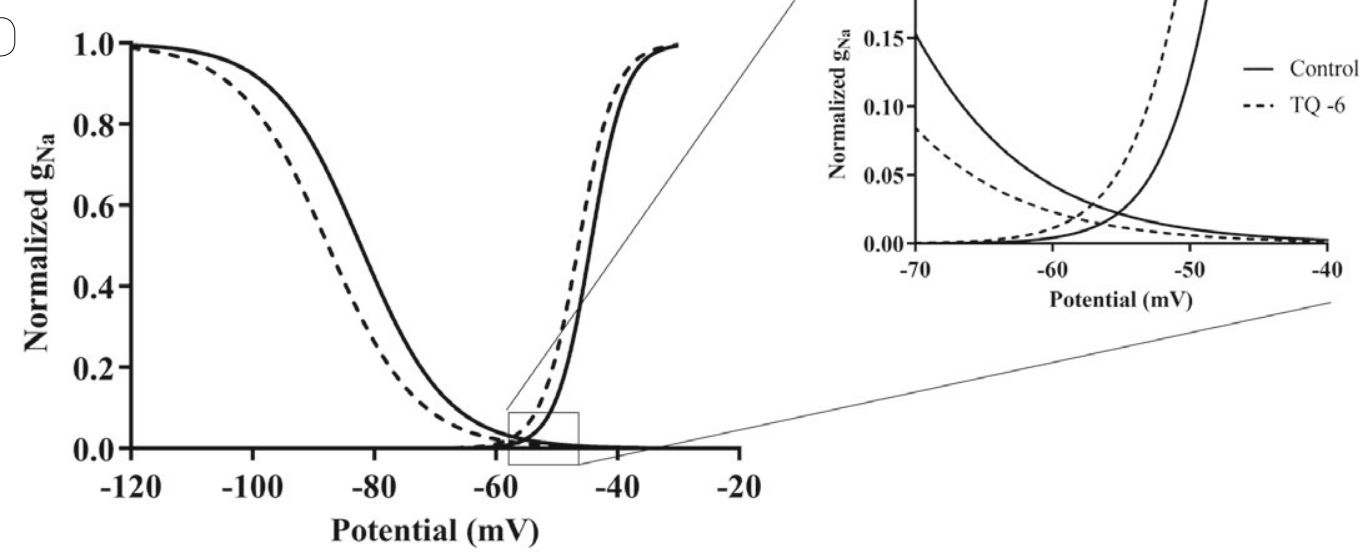

Fig. 3. Effect of TQ administration voltage-dependent activation and inactivation kinetics of $\mathrm{Na}^{+}$channels. Data fit was performed according to the Boltzmann function. Activation kinetics of TQ-6 in (A) and TQ-5 in (B). Inactivation kinetics of TQ-6 in (C) and TQ-5 in (D). Na ${ }^{+}$window current for TQ-6 and control in (E). Due to shifting of activation and inactivation curves to the left, window current also shifted to the left. $\# p<0.05$ versus control ( $n=9$ cells for TQ-6 and $n=8$ for TQ-5).

GTP $(\mathrm{pH}=7.22)$ and standard Tyrode's solution for extracellular solution was used. Pre-pulse to $-45 \mathrm{mV}$ from a holding potential of $-80 \mathrm{mV}$ was applied to inactivate $\mathrm{Na}^{+}$current. Then, L-type $\mathrm{Ca}^{2+}$ current density $\left(\mathrm{I}_{\mathrm{CaL}}\right)$ was recorded by applying $300 \mathrm{~ms}$ depolarizing pulses at $0 \mathrm{mV}$.

\section{Statistics}

Experimental data are expressed as mean \pm SEM. Differences between groups have been analysed by one-way ANOVA and paired Student's t-test. Differences were considered statistically significant when $\mathrm{p}<0.05$. 
Tab. 1. Steady-state activation properties of sodium currents for both TQ concentrations.

\begin{tabular}{lcccc}
\hline & Control & TQ-6 & Control & TQ-5 \\
\hline $\mathrm{V}_{50}(\mathrm{mV})$ & $-44.71 \pm 0.95$ & $-46.42 \pm 1.16^{\#}$ & $-45.85 \pm 1.28$ & $-49.29 \pm 1.61^{\text {\# }}$ \\
Slope & $1.49 \pm 0.17$ & $1.84 \pm 0.09^{\#}$ & $1.29 \pm 0.21$ & $1.56 \pm 0.24^{\#}$ \\
\hline
\end{tabular}

$\# \mathrm{p}<0.05$ versus control ( $\mathrm{n}=16$ cells for TQ-6 and $\mathrm{n}=9$ for TQ-5)

Tab. 2. Steady-state inactivation properties of sodium currents for both TQ concentrations.

\begin{tabular}{lcccc}
\hline & Control & TQ-6 & Control & TQ-5 \\
\hline $\mathrm{V}_{50}(\mathrm{mV})$ & $-81.29 \pm 5.722$ & $-86 \pm 5.53^{\text {\# }}$ & $-82.83 \pm 3.886$ & $-90.69 \pm 6.515^{\text {\# }}$ \\
Slope & $-5.719 \pm 1.029$ & $-5.604 \pm 0.5664$ & $-5.618 \pm 0.6052$ & $-5.876 \pm 1.266$ \\
\hline
\end{tabular}

$\# \mathrm{p}<0.05$ versus control $(\mathrm{n}=9$ cells for TQ- 6 and $\mathrm{n}=8$ for TQ-5).

\section{Results}

\section{Effects of TQ on action potential of ventricular myocytes}

The effect of TQ (Sigma-Aldrich, Germany) on AP was assessed in freshly isolated rat ventricular myocytes. Sample recordings of AP obtained in response to $10^{-6} \mathrm{M}$ (TQ-6) and $10^{-5} \mathrm{M}$ (TQ-5) concentrations of TQ are shown in Figure 1. Exposure to both concentrations of TQ significantly prolonged the AP durations (APD) presented as $\mathrm{APD}_{25}, \mathrm{APD}_{50}, \mathrm{APD}_{75}$ and $\mathrm{APD}_{90}$ (Figure $1 \mathrm{~A}$ and $\mathrm{B}$, respectively).

In addition, TQ administration caused a significant reduction ( $\sim 14.53 \%$ for TQ- 6 and $\sim 19.44 \%$ for TQ- 5 ) in the peak value of AP in ventricular myocytes. It has also achieved a minor but significant depolarizing effect on the resting membrane potential of ventricular myocytes during TQ-5 perfusion but not that of TQ-6.

\section{Effects of TQ on sodium currents of ventricular myocytes}

$\mathrm{I}_{\mathrm{Na}}$ was examined to check whether the change in the peak of AP is relevant to these currents. As shown in Figures 2A and B, the peak value of $\mathrm{I}_{\mathrm{Na}}$ current decreased significantly during both concentrations of TQ (Figs 2C and D).

Then, $\mathrm{Na}^{+}$channel kinetics were also examined since there was a remarkable shift in the voltage-current relation curve of $\mathrm{I}_{\mathrm{Na}}$ current following TQ administration. Voltage-dependent activation and inactivation kinetics were analysed for TQ-6 and TQ-5 concentrations, respectively (Fig. 3A-D). TQ elicited significant changes in $\mathrm{Na}^{+}$kinetics. The half-maximal potential $\left(\mathrm{V}_{50}\right)$ of activation and inactivation (Tabs 1 and 2, respectively) decreased significantly for both concentrations of TQ, while there was a significant increase in the activation slope (Tab. 1). Accordingly, as can be seen in Figure 3, TQ administration dose-dependently achieved a leftward shift to more negative potentials in both the activation and inactivation curves. However, $\mathrm{Na}^{+}$window current did not change by either concentration of TQ.

Effects of TQ on transient outward potassium currents of ventricular myocytes

Compared to baseline control, peak value of $\mathrm{I}_{\text {to }}$ was significantly decreased in response to both concentrations of TQ (7.67 \% at $10^{-6} \mathrm{M}$ and $12.8 \%$ at $10^{-5} \mathrm{M}$ ) (Figs $4 \mathrm{~A}$ and $\mathrm{B}$ ). The extent of change in $\mathrm{I}_{\text {to }}$ of ventricular myocytes for both concentrations of TQ is presented in Figure 4B. Moreover, kinetics of currents were also examined by exponential fit (20), and it was observed that the slow time constant of the current was reduced (Fig. 4C) while there was no significant change in the fast time constant (in ms: $31.82 \pm 19.25$ in control vs $32.04 \pm 18.25$ in TQ-5).

Effects of TQ on L-type calcium current and $\beta$-adrenergic response of ventricular myocytes

Both TQ concentrations were given to the cell, and changes in $\mathrm{I}_{\mathrm{CaL}}$ were recorded (Fig. 5A). Perfusion of ventricular myocytes with TQ induced a significant and dose-dependent reduction in $\mathrm{I}_{\mathrm{CaL}}$ of ventricular myocytes. The percentage of change in $\mathrm{I}_{\mathrm{CaL}}$ at two concentrations of TQ is given in Figure 5B. TQ achieved 11.55 $\%$ and $17.36 \%$ decrease in $\mathrm{I}_{\mathrm{CaL}}$ at $10^{-6}$ and $10^{-5} \mathrm{M}$, respectively.
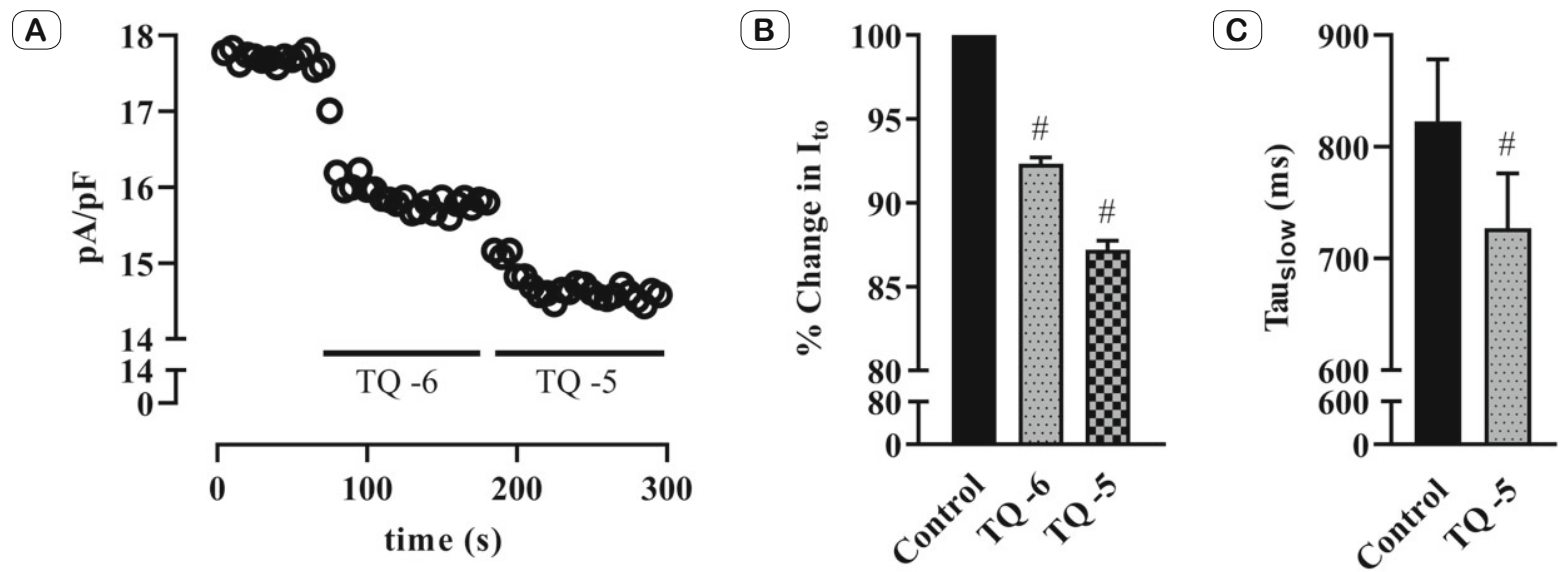

Fig. 4. Effects of TQ on transient outward potassium currents. Sample recordings and graphical demonstration of TQ-6 and TQ-5 in (A) and (B) respectively. Mean data for control and TQ-5 cells showing the slow time constants in (C). Data are represented as mean \pm SEM. \# $\mathbf{p}<0.05$ versus control ( $n=12$ cells for TQ-6 and $n=9$ for TQ-5). 
A

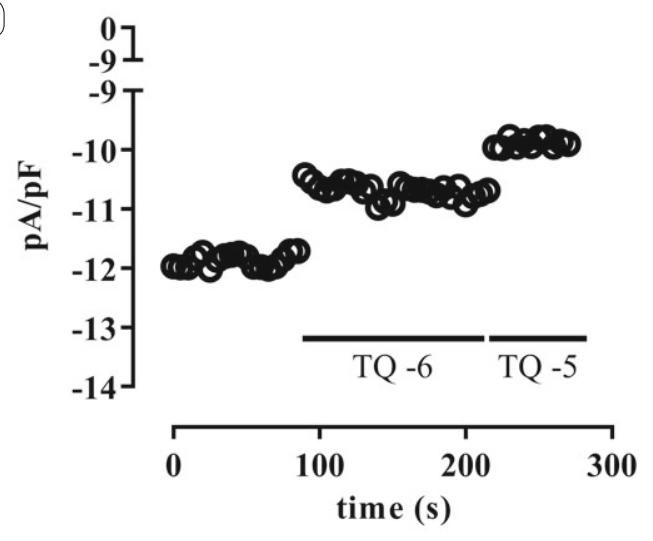

(B)

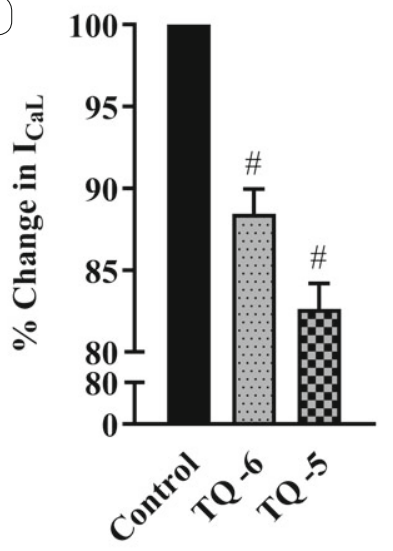

(C)

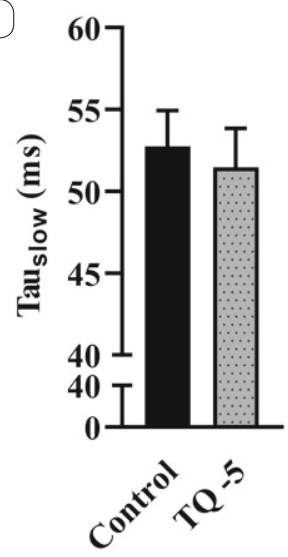

Fig. 5. Effects of TQ on $I_{C a L}$ currents. Sample recordings and graphical demonstration of TQ-6 and TQ-5 in (A) and (B) respectively. Mean data for control and TQ-5 cells showing the fast time constants in (C). Data are represented as mean \pm SEM. \# $p<0.05$ versus control ( $n=16$ cells for TQ-6 and $n=16$ for TQ-5).

A

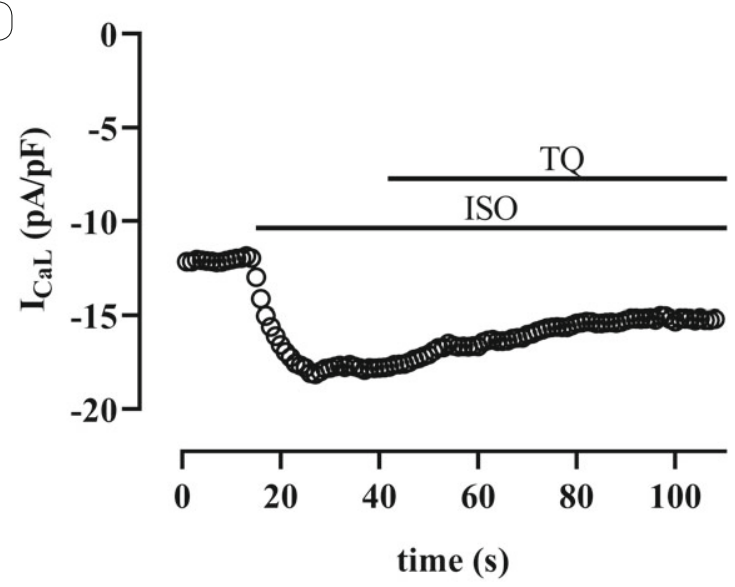

B

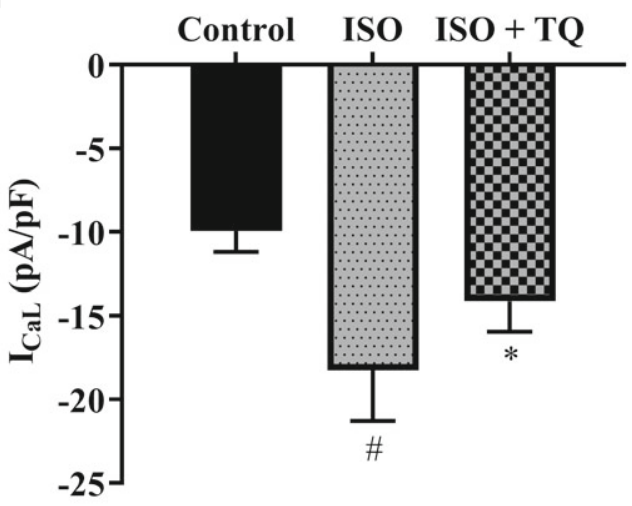

Fig. 6. TQ attenuates the isoproterenol (ISO)-induced increase in L-type $\mathrm{Ca}^{2+}$ currents in ventricular myocytes. After stimulatory effect of $\mathbf{1 0}^{-6}$ M ISO, TQ-6 applied and it shows inhibitor effect on $\beta$-adrenergic system. Data are represented as mean \pm SEM. * $p<0.05$ versus baseline values and \# $p<0.05$ versus ISO ( $n=4$ cells).

Kinetic analysis of current recorded at $0 \mathrm{mV}$ were also examined and it was observed that the time constant of neither fast nor slow component of inactivation changed significantly (Fig. 5C). Lastly, to investigate whether TQ has any effect on the adrenergic system of ventricular myocytes, TQ-6 was applied following the ISO (Sigma-Aldrich, Germany)-induced increase in $\mathrm{I}_{\mathrm{CaL}}$. As shown in Figure 6 TQ has an inhibitory effect on the $\beta$-adrenergic response of $\mathrm{I}_{\mathrm{CaL}}$.

\section{Discussion}

The present study demonstrated for the first time that TQ has significant modulatory effects on electrophysiological properties of rat ventricular myocytes. Namely, the APD was prolonged whereas the peak value of AP significantly decreased. We have also revealed the ionic currents and kinetic alterations underlying these changes in AP characteristics. Finally, in this study, acute TQ treatment has been shown to alleviate the ISO-induced increase in $\mathrm{I}_{\mathrm{CaL}}$ current which infers it has an inhibitory effect on $\beta$-adrenergic responses of ventricular myocytes.

First of all, AP characteristics were examined, and it was seen that the peak value of AP decreased and the APD increased significantly depending on the concentration of TQ. Since voltagedependent $\mathrm{Na}^{+}$channels are primarily responsible for the depolarization phase and the peak value of AP, this apparent decrease in peak value is due most likely to depressed $\mathrm{Na}^{+}$channel currents. Consistent with this explanation we observed significant decrease in $\mathrm{I}_{\mathrm{Na}}$ density along with significant shift in voltage-dependency of $\mathrm{Na}^{+}$channels in ventricular myocytes following TQ administration. Any significant change in the peak or duration of the AP under pathological conditions can result in serious functional abnormalities due to the altered excitability of the cardiac myocytes (21). 
Although Asgharzadeh et al (22) reported that TQ has beneficial effects on CVD, our results show that TQ may exert an opposite effect by reducing $\mathrm{I}_{\mathrm{Na}}$ and prolonging APD.

For cardiac $\mathrm{Na}^{+}$channels, there is a region where the steadystate inactivation and activation curves overlap which is called 'window' current or persistent $\mathrm{I}_{\mathrm{Na}}$ current. Although the contribution of this current to total $\mathrm{I}_{\mathrm{Na}}$ current is relatively small, any change in this persistent $I_{\mathrm{Na}}$ current may have a significant effect on the AP morphology and thus increase the likelihood of arrhythmia $(4,23,24)$. In this study, TQ shifted the window current to more negative potentials. As a result of this shift, $\mathrm{Na}^{+}$channels are tending to be opened at more negative potential values which may increase the tendency to develop cardiac arrhythmias (25). Accordingly, when the $\mathrm{Na}^{+}$channel kinetics were examined, we observed significant decreases in $\mathrm{V}_{50}$ and slope values of both activation and inactivation curves. As a result, TQ acts not only on $\mathrm{I}_{\mathrm{Na}}$ amplitude but also alters channel kinetics in cardiomyocytes. On the other hand, $\mathrm{Na}^{+}$channels may have no effect on prolonging the APD since the width or total area of the window did not change significantly.

We measured $\mathrm{I}_{\text {to }}$ and $\mathrm{I}_{\mathrm{CaL}}$ currents to find the main culprit of TQ-induced prolongation in APD since they are the major ionic fluxes underlying AP repolarization. Although we found a significant reduction in both currents in response to TQ administration, the effect of the reduction in $\mathrm{I}_{\text {to }}$ on APD will be more pronounced than that of $\mathrm{I}_{\mathrm{CaL}}$ current, as it contributes more to AP repolarization in rat myocytes (20). Hence, despite the opposite effects of these currents, prolongation was eventually measured in the APD. These results seem to be interesting for a substance that is claimed to be beneficial for diseases such as diabetes, pathological hypertrophy and heart failure characterized by prolonged APD $(3,16$, $26,27)$. The findings of this study imply that TQ may aggravate the risk of pathological events in certain cardiovascular diseases.

Finally, we investigated whether TQ influences the $\beta$-adrenergic response of $\mathrm{L}$-type $\mathrm{Ca}^{2+}$ channels since $\beta$-adrenergic signalling is very important for the regulation of cardiac muscle activities. Our findings showed that TQ alleviated the stimulatory effect of ISO on $\mathrm{I}_{\mathrm{CaL}}$. Having an inhibitory effect on the $\beta$-adrenergic system TQ can be effective in the treatment of diseases with upregulated $\beta$-adrenergic signalling such as pathological cardiac hypertrophy and dilated cardiomyopathy $(28,29)$. Asoom et al (30) have demonstrated an inotropic impact in ventricular myocytes with long-term supplementation of TQ which is attributed to enhanced sensitivity of contractile proteins to cytosolic $\mathrm{Ca}^{2+}$ rather than modulation of $\beta$-adrenergic pathway because there were no significant differences between the relaxation time of control and TQ groups myocytes. In contrast, we demonstrated that acute TQ treatment has an inhibitory effect on the $\beta$-adrenergic response of ventricular myocytes. However, these contradictory findings may arise due to the difference between acute and chronic effects of TQ.

In our study, we investigated the effects of the acute application of plant-derived TQ, which is a very popular ingredient of NS, on the electrophysiological parameters underlying excitationcontraction coupling (ECC) of cardiomyocytes. Our data showed that TQ not only changed the AP morphology and underlying ionic currents but also alleviated the $\beta$-adrenergic response of ventricular myocytes. These results indicate that TQ may be considered as a therapeutic agent in cases where the $\beta$-adrenergic system is over-activated, but it can be harmful in healthy individuals and pathological situations where the $\beta$-adrenergic system is not overactivated. However, to address this question, the effects of TQ on parameters modulating ECC in cardiac myocytes should also be demonstrated in chronic animal models.

\section{References}

1. Farkhondeh T, Samarghandian S, Azimin-Nezhad M, Samini F. Effect of chrysin on nociception in formalin test and serum levels of noradrenalin and corticosterone in rats. Int J Clin Exp Med 2015; 8: 2465-2470.

2. Samarghandian S, Azimi-Nezhad M, Borji A, Farkhondeh T. Effect of crocin on aged rat kidney through inhibition of oxidative stress and proinflammatory state. Phyther Res 2016; 30: 1345-1353. https:// doi.org/10.1002/ptr.5638.

3. Farkhondeh T, Samarghandian S, Borji A. An overview on cardioprotective and anti-diabetic effects of thymoquinone. Asian Pac J Trop Med 2017; 10: 849-854. https://doi.org/10.1016/j.apjtm.2017.08.020.

4. Shafiq H, Ahmad A, Masud T, Kaleem M. Cardio-protective and anticancer therapeutic potential of Nigella sativa. Iran J Basic Med Sci 2014; 17: 967-980. https://doi.org/10.22038/ijbms.2015.3853.

5. Aggarwal BB, Kunnumakkara AB, Harlkumar KB, Tharakan ST, Sung B, Anand P. Potential of spice-derived phytochemicals for cancer prevention. Planta Med 2008; 74: 1560-1569. https://doi. org/10.1055/s-2008-1074578.

6. Alenzi FQ, El-Sayed El-Bolkiny Y, Salem ML. Protective effects of Nigella sativa oil and thymoquinone against toxicity induced by the anticancer drug cyclophosphamide. Br J Biomed Sci 2010; 67: 20-28. https: //doi.org/10.1080/09674845.2010.11730285.

7. Gali-Muhtasib H, Ocker M, Kuester D, Krueger S, EI-Hajj Z, Diestel A et al. Thymoquinone reduces mouse colon tumor cell invasion and inhibits tumor growth in murine colon cancer models. J Cell Mol Med 2008; 12: 330-342. https: //doi.org/10.1111/j.1582-4934.2007.00095.x.

8. Liu X, Park JH, Abd El-Aty AM, Assayed ME, Shimoda M, Shim JH. Isolation of volatiles from Nigella sativa seeds using microwaveassisted extraction: Effect of whole extracts on canine and murine CYP1A. Biomed Chromatogr 2013; 27: 938-945. https: //doi.org/10.1002/ bmc. 2887.

9. Mansour MA, Nagi MN, El-Khatib AS, Al-Bekairi AM. Effects of thymoquinone on antioxidant enzyme activities, lipid peroxidation and dtdiaphorase in different tissues of mice: A possible mechanism of action. Cell Biochem Funct 2002; 20: 143-151. https: //doi.org/10.1002/cbf.968.

10. Periasamy VS, Athinarayanan J, Alshatwi AA. Anticancer activity of an ultrasonic nanoemulsion formulation of Nigella sativa L. essential oil on human breast cancer cells. Ultrason Sonochem 2016; 31: 449-455. https: //doi.org/10.1016/j.ultsonch.2016.01.035.

11. Badary OA, Taha RA, Gamal El-Din AM, Abdel-Wahab MH. Thymoquinone is a potent superoxide anion scavenger. Drug Chem Toxicol 2003; 26: 87-98. https: //doi.org/10.1081/DCT-120020404.

12. Daba MH, Abdel-Rahman MS. Hepatoprotective activity of thymoquinone in isolated rat hepatocytes. Toxicol Lett 1998; 95: 23-29. https: //doi.org/10.1016/S0378-4274(98)00012-5. 
13. Nagi MN, Mansour MA. Protective effect of thymoquinone against doxorubicin-induced cardiotoxicity in rats: A possible mechanism of protection. Pharmacol Res 2000; 41: 283-289. https: //doi.org/10.1006/ phrs.1999.0585.

14. Yildiz Pehlivan D, Durdagi G, Oz Oyar E, Akyol S, Ozbek M. The effects of melatonin and thymoquinone on doxorubicin-induced cardiotoxicity in rats. Bratislava Med J 2020; 121: 753-759. https: //doi. org/10.4149/BLL_2020_123.

15. Al Wafai RJ. Nigella Sativa and thymoquinone suppress cyclooxygenase-2 and oxidative stress in pancreatic tissue of streptozotocin-induced diabetic rats. Pancreas 2013; 42: 841-849. https: //doi.org/10.1097/ MPA.0b013e318279ac1c.

16. Liu H, Liu HY, Jiang YN, Li N. Protective effect of thymoquinone improves cardiovascular function, and attenuates oxidative stress, inflammation and apoptosis by mediating the PI3K/Akt pathway in diabetic rats. Mol Med Rep 2016; 13: 2836-2842. https: //doi.org/10.3892/mmr.2016.4823.

17. Randhawa MA, Alghamdi MS, Maulik SK. The effect of thymoquinone, an active component of Nigella sativa, on isoproterenol induced myocardial injury. Pak J Pharm Sci 2013; 26: 1215-1219.

18. Al-Shabanah OA, Badary OA, Nagi MN, Al-Gharably NM, AlRikabi AC, Al-Bekairi AM. Thymoquinone protects against doxorubicininduced cardiotoxicity without compromising its antitumor activity. J Exp Clin Cancer Res 1998; 17: 193-198.

19. Olgar Y, Ozturk N, Usta C, Puddu PE, Ozdemir S. Ellagic acid reduces L-type $\mathrm{Ca} 2+$ current and contractility through modulation of NOGC-cGMP pathways in rat ventricular myocytes. J Cardiovasc Pharmacol 2014; 64: 567-573. https: //doi.org/10.1097/FJC.0000000000000153.

20. Ozturk N, Yaras N, Ozmen A, Ozdemir S. Long-term administration of rosuvastatin prevents contractile and electrical remodelling of diabetic rat heart. J Bioenerg Biomembr 2013; 45: 343-352. https: //doi.org/10.1007/ s10863-013-9514-z.

21. Makielski JC. Late sodium current: A mechanism for angina, heart failure, and arrhythmia. Trends Cardiovasc Med 2016; 26: 115-122. https: //doi.org/10.1016/j.tcm.2015.05.006.
22. Asgharzadeh F, Bargi R, Beheshti F, Hosseini M, Farzadnia M, Khazaei M. Thymoquinone prevents myocardial and perivascular fibrosis induced by chronic lipopolysaccharide exposure in male rats. J Pharmacopuncture 2018; 21: 284-293. https: //doi.org/10.3831/KPI.2018.21.032.

23. Saint DA. The cardiac persistent sodium current: An appealing therapeutic target? Br J Pharmacol 2008; 153: 1133-1142. https: //doi. org/10.1038/sj.bjp.0707492.

24. Moreno JD, Clancy CE. Pathophysiology of the cardiac late Na current and its potential as a drug target. J Mol Cell Cardiol 2012; 52: 608-619. https: //doi.org/10.1016/j.yjmcc.2011.12.003.

25. Frenz CT, Hansen A, Dupuis ND, Shultz N, Levinson SR, Finger TE et al. Nav1.5 sodium channel window currents contribute to spontaneous firing in olfactory sensory neurons. J Neurophysiol 2014. https: // doi.org/10.1152/jn.00154.2014.

26. Fan Z, Lv N, Luo X, Tan W. Isosteviol prevents the prolongation of action potential in hypertrophied cardiomyoctyes by regulating transient outward potassium and L-type calcium channels. Biochim Biophys Acta- Biomembr 2017; 1859: 1872-1879. https: //doi.org/10.1016/j. bbamem.2017.04.011.

27. Tauseef Sultan M, Butt MS, Anjum FM. Safety assessment of black cumin fixed and essential oil in normal Sprague dawley rats: Serological and hematological indices. Food Chem Toxicol 2009; 47: 2768-2775. https: //doi.org/10.1016/j.fct.2009.08.011.

28. Ciccarelli M, Santulli G, Pascale V, Trimarco B, Iaccarino G. Adrenergic receptors and metabolism: Role in development of cardiovascular disease. Front Physiol 2013; 4 OCT: 265. https: //doi.org/10.3389/ fphys.2013.00265.

29. Leosco D, Parisi V, Femminella GD, Formisano R, Petraglia L, Allocca $\mathbf{E}$ et al. Effects of exercise training on cardiovascular adrenergic system. Front Physiol 2013; 4: 348. https: //doi.org/10.3389/fphys.2013.00348.

30. Asoom LI Al, Al-Hariri MT. Cardiac Inotropic Effect of Long-Term Administration of Oral Thymoquinone. Evidence-Based Complement Altern Med 2019; 2019. https: //doi.org/10.1155/2019/8575136.

Received November 4, 2020. Accepted November 25, 2020. 